\title{
Integrity among Academics: Concept, Challenge and Way Forward
}

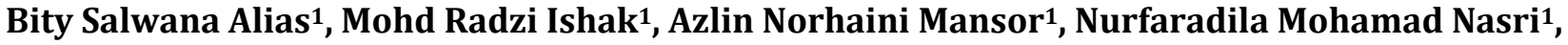 \\ Zaida Nor Zainudin²
}

${ }^{1}$ Faculty of Education, Universiti Kebangsaan Malaysia, Selangor, Malaysia

${ }^{2}$ Faculty of Educational Studies, Universiti Putra Malaysia, Selangor, Malaysia

Email: bity@ukm.edu.my

How to cite this paper: Alias, B. S., Ishak, M. R., Mansor, A. N., Nasri, N. M., \& Zainudin, Z. N. (2019). Integrity among Academics: Concept, Challenge and Way Forward. Creative Education, 10, 2760-2768. https://doi.org/10.4236/ce.2019.1012202

Received: October 18, 2019

Accepted: November 25, 2019

Published: November 28, 2019

Copyright $\odot 2019$ by author(s) and Scientific Research Publishing Inc. This work is licensed under the Creative Commons Attribution International License (CC BY 4.0).

http://creativecommons.org/licenses/by/4.0/

(c) (i) Open Access

\begin{abstract}
The degree of integrity among academics is yet to be determined because there is no proper instrument for such measurement. The purpose of this paper is therefore to identify elements that can measure integrity, as well as develop integrity framework or model. Among the themes discussed in this paper are, what are the theories, models and concepts related to integrity, previous studies on integrity and subsequent discussions on the development process of the model that are appropriate for measuring integrity. This concept paper concludes that integrity can be measured based on the values required for integrity. The implication of this concept paper is that the values that are inherent in a person determine their level of integrity. This concept paper recommends that integrity should be measured over time. It is not only to produce an index of integrity but also to remind academics of the appropriate values and practices in fulfilling their responsibilities. Furthermore, ongoing exposures to integrity instruments may prevent misconceptions about integrity that only associated with corruption, abuse of power, unprofessional and inaccurate matters in terms of duties, responsibilities, roles or positions held.
\end{abstract}

\section{Keywords}

Education, Integrity, Academics, Concept, Challenge, Way Forward

\section{Introduction}

The issue of integrity among civil servants is never-ending. However, it is important to note that not all civil servants are not practicing integrity as their culture. Most civil servants continue to uphold the principle of integrity in carrying out their duties and responsibilities. Integrity policies imposed on public services 
are also not new. Among the policies are Clean, Efficient and Trusted Campaign (1982), Leadership by Example Campaign (1983), Implementation of Islamic Values Policy (1985), Islamic Work Ethic (1987), Excellent Work Culture (1989), Quality Award (1990), Client Charter (1993), MS ISO 9000 (1996), Excellent Service Award (2002), Key Performance Indicators (KPIs) Islam Founded (2005) and more. In addition to policy, many public service circuits are distributed as a guide to cultivate integrity such as the Public Administration Development Circular. No. 1 (2008), Customer Relation Management Guide, Public Administration Development Circular No. 1 (2009), Improvement of Public Complaints Management Process, Public Service Progress Circular No. 2 (1996), ISO 9000: 2000 Implementation Guide, Service Circular No. 5 (2007), Office Management Guide and more.

\section{The Concept of Integrity}

Based on the efforts made, integrity should no longer be an issue, but should be understood and practiced. What is integrity? Institutions of Integrity Malaysia (IIM) define integrity as an individual trait based on pure values such as honest, truthful, trustworthy, just, responsible, transparent, efficient and wise. The National Integrity Plan (PIN) defines integrity as the superior quality that exists both individually and collectively. In Islam, integrity is truthful, trustworthy, honest, sincere, loyal, responsible, decisive, just, efficient, diligent, wise, firm, personal, noble, and virtuous, and such as the nature of the Messenger of Allah is truthful (siddiq), trustworthy (amanah), deliver (tabligh), and wise (fatanah). A person of integrity will do things in an ethical way, with acceptable values and beliefs. Civil servants with positions or responsibilities are entrusted to act honestly in their jurisdiction and duties must be transparent, have no personal conflict, authority, accountable and adhere to all applicable laws and regulations so that the public's trust in the public servant is not impaired, but stable and harmony.

Public agencies are built up with the essential target of meeting the needs of the people and country. To accomplish this target, a high-quality public service delivery system is required for effective government policies to be implemented. The significance of integrity to the public service is to make proficient and disciplined public administration and services through the utilization of moral values that can overcome problems and weaknesses in different parts of governance such as financial administration, treatment of disciplinary cases, corruption, abused of intensity and unlawful abuse by regulation, legislation and religion (National Integrity Plan, 2004).

In short, integrity can be defined as honesty and sincerity as well as perfection. The Oxford Dictionary (2008) outlines four key features of the concept of integrity, which are wholeness, soundness, uprightness and honesty. Among government's effort to increase integrity in the delivery of public services are the establishment of the Public Complaints Bureau (BPA) in 2000, which allowed the 
public to submit complaints directly to the Prime Minister's Department (BPA, 2010), and the drafting of the National Integrity Plan (PIN) in 2004. In accordance to this, integrity has been defined more precisely by National Integrity Plan 2004 (PIN 2004) which carries the meaning of the highest quality that exists among individuals and is based on the principle of honesty and moral practice (Mazilan et al., 2005). Based on this definition, integrity can be understood as the key to achieve quality work that is entrusted to an individual or organization based on the nature of integrated and comprehensive work (Ab. Rahman, 2005). Integrity should be a pledge to high good standards in carrying out tasks at the individual or organizational level. At individual level, the concept of integrity means that an employee needs to demonstrate a balance between what is being said and what is being done, also to act in accordance with moral, ethical and legal principles, to prioritize public interest above his or her own will, and to do quality and proper work. At the organizational level on the other hand, integrity is reflected in the implementation and articulation of code of ethics, client charters, work processes and adherence to the best practices.

Besides, to fortify integrity in the delivery of public services, multi policies have been implemented by the government such as the Public Service Ethics Policy and the Excellent Service Concepts; Clean, Efficient and Trusted Policies; Policy and Ethics in Public Service; Implementation of Islamic Values in Public Service; and the Twelfth pillar Policy. The basics have been practiced in multi programs at the department organization level such as the use of tags, customer charts, work ethic code drafting, work manuals, desk files, open office systems, integrity management modules, customer meeting days, work rounds and the establishment of monitoring teams (Ab. Rahman, 2005, Mazilan et al., 2005, Sulaiman, 2005, Mohd Tap, 2008). The definition is similar to Islamic doctrine, which describe integrity as being honest, trustworthy, sincere, loyal, responsible, decisive, fair, competent, diligent, wise, firm, and self-confident.

\section{The Challenge}

The discussion on integrity can never end. The question is does it shows that its integrity has not been fully addressed? Until now, there is no absolute answer to this. However, many organizations try their best to inculcate the culture of integrity. The same is happening in most of the higher education. The latest trend is to produce integrity index. A group of researchers is now in the process of producing integrity index. However, it becomes a challenge since there is no proper instrument for such measurement. Due to that, based on the values that they have determined, the researchers have developed an instrument, collected the data and soon analyses the data to come out with the integrity index. However, in the process of collecting data, the re-searchers faced a lot of challenges including the cooperation of the respondents in filling up the form.

Another challenge is a misconception on integrity. People always relate integrity to corruption, abuse of power, and taking away the unjust (Malaysian An- 
ti-Corruption Commission Act, 2009). Therefore, clarifying the true concept of integrity to the society is necessary. The responsibility is not imposed on one party only but instead a responsibility of all including the mass media to educate the society on the values of integrity.

For the government sector, the challenge of establishing and sustaining best practices with integrity persisted. The higher ratio of civil servants to the population should be able to demonstrate the efficiency and effectiveness of the government service delivery system to the people (OECD, 2009). Unfortunately, the performance and integrity of the civil service in Malaysia are still at a low level.

Research on public complaints reports from 2000 to 2004 (Royal Malaysian Police Travel and Management Improvement Commission Report, 2005) found that, public agencies related to enforcement such as the Royal Malaysian Police (PDRM), the Road Transport Department (JPJ) and Royal Malaysian Customs (KDRM) were among the top agencies to receive public complaints. In 2000, the agencies with the highest complaints were PDRM (1208 complaints), JPJ (843 complaints), and Land/District Office and Municipal Council (495 complaints respectively). Some of these agencies, such as PDRM, remain problematic by recording the highest public complaint data between 2000 and 2004 (Department of National Statistics, 2001-2004). The 2002 Public Perception of Corruption Research report cited PDRM, MOH, JPJ, Immigration and licensing-related agencies as the top agencies involved in corruption and abuse of power (in the Report of the PDRM Travel and Management Commission Report, 2005).

These show that past studies and reports on integrity generally focus on issues of corruption, malpractice and abuse of power. This article argues that "public complaints" can technically serve as an important indicator in understanding the integrity of civil servants. This is because a public complaint is an expression of public disappointment with the service qualities provided by government workers or agencies (Dobel, 1990, Amstrong, 2005). Increasing in public complaints technically represent deterioration in the level of service integrity, especially when complaints and investigations have merit and civil servants are subject to disciplinary action. The use of public complaints as an integrity test is in line with the emphasis of the Public Complaints Bureau (BPA), which attests that one of the triumphs of expanding integrity is the ability to lessen and resolve com-plaints (BPA, 2010).

There is also a study that discussed the integrity of civil servants in JPJ based on the records of complaints received by the agency from 2008 to 2011 . The four main objectives of the article were to review the com-plaints trend, describe the contents of the complaint, determine the merits of complaints and examine the impact of complaints on the careers of civil servants involved. Data obtained from JPJ Headquarters, Putrajaya covers nine categories of public complaints including abuse of power, delay in action, no action, failure to comply, quality of counter and telephone service, failure to comply with procedure, unresponsiveness, unfair action and lack of public facilities. The results show that the number 
of public complaints received by the JPJ over the past four years shows a decline in integrity. A review of the content of the complaint found that about 53-54 percent of complaints received had a basis or merit whether it involved minor or serious cases. For serious cases that have been decided or are still under trial, various disciplinary actions have been instituted by the agency including removal, suspension of employment, resilience, delay in wage movement and demotion. To reduce criticize and increase the integrity of services, various proposals have been submitted such as the revision of the JPJ strategic plan, improvement of human resource management practices, reinforcing of ICT systems and work procedures, integrated complaints management systems as well as continuous monitoring and testing measures.

A study to determine the need to instil an understanding of the value of integrity among staff administration at UiTM has been done since 2004. The special committee, named as Management Compliance Committee (DOSH), followed by a Vice-Chancellor Circular No.20/2007on April 30, 2007, directed each staff member to attend the Integrity Awareness Program. Among other things, the contents of the circular are on the aim of the National Integrity Plan (PIN), launched by the Prime Minister on April 23, 2004, to form a strong community of moral and ethical values, with the citizens having a strong sense of religious and spiritual values and upheld by high moral values. The purpose of the program is also to educate, to inculcate a positive value (mahmudah) to the administrative staff, and to drive civil servants to always be trustworthy, sincere, honest and responsible in preserving and empowering the image of the department. The concepts, definitions, policies and guidelines of integrity are then implemented among UiTM administration staff through platforms such as training sessions, lectures, workshops, and Human Capital Development (PMI) program. Based on the Integrated Data Centre (PSMB), by May 1, 2011, the knowledge and the practice of integrity values among UiTM administrative staff was significantly increased in 2009. The university then provided a module to guide their academic staff to achieve excellence, uphold the values and ethics that they supposed to serve as religious values. The purpose is also to strengthen and disseminate Islamic understanding and thought by focusing on the topic of spiritual development and applying the values of integrity based on the Quran and al-Hadith. Since then, integrity is embedded in UiTM's premier culture as its core values and ethics.

A study entitled "The importance of integrity culture and work ethics in Malaysian organizations: A preliminary study" by Megat Ayop and Abd. Halim (2016a) stated that it should go without saying that integrity and ethics in the workplace are two indispensable qualities in the public service of any nation. Erosion of the two values among civil servants will lead to mismanagement and misconduct within the organization. This study overviewed the progress of the National Integrated Plan (2014) with the special reference to the Malaysian Royal Police organization (PDRM). A primary data was gathered from a questionnaire administered to 760 of the PDRM staff and police personnel in the state of 
Perak. The findings revealed that, majority of respondents testified to and reaffirmed the imperative of integrity and work ethic being consistently practiced by all Malaysian public sector employees and civil servants.

A study by Nik Hairi et al. (2012) expressed that the performance and integrity of government workers in Malaysia are still at a critical stage. Based on International Corruption Perception Index (CPI) Report from 1995 to 2010, Malaysia is among the country with the highest rates of corruption, ranking at 22nd (1995) to 37th (2003) and 56th for 2010 (International Transparency 1995-2010). Over the last 15 years, the Malaysian CPI Index's average score has plummeted from 5.28 points (1995) to 4.4 points in 2010. This indicates that over the years, issues such as corruption and inefficiencies in public service delivery have become more serious. This fact is supported by several domestic studies such as the conclusion of experts Ernst and Young International (1996) who found that government officers committed 78 percent of fraudulent cases in government agencies. This finding is consistent with the findings of the Federal Government Report (2005) which showed that civil servants involved in various cases of misconduct such as absenteeism (61.4\%), disciplinary violations (13.1\%), misconduct (12.6\%), drugs abused (2.3\%), receiving bribes and entertainment bribes (2.3\%), serious indebtedness $(0.3 \%)$ and wrongdoing on property beyond their career ability $(0.1 \%)$.

Another investigation by Megat Ayop and Abd. Halim (2016b) entitled "The idea of integrity in the department of Royal Malaysian Police: A preliminary study" stated that integrity is one of the most important characteristics of an organizational culture that can ensure service quality and excellence in the organization's system. Megat Ayop and Abd. Halim also said that RMP has been trying to improve and strengthen the integrity of police personnel in order to meet the security and law enforcement needs of the state and the society. However, according to a report issued by the Public Complaints Bureau (2014) and the Enforcement Agency Integrity Commission (2014), Malaysian police obtained many complaints from the public regarding the deterioration in their service presentation system and thus their integrity. Therefore, they conducted a study by collecting data using questionnaires and interviews with 760 RMP members and officers. The study, which examined the two methods of integrity enhancement among members of the RMP, namely the organizational culture, and the individual integrity, showed that the organizational culture seems to be more relevant in explaining the integrity problems in RMP as it showed a great influence on the police attitudes and behaviour.

\section{The Way Forward}

In order to ensure integrity becomes a culture in all government agencies, individuals and organizations are required to practice good values such as honest, truthful, trustworthy, fair, responsible, transparent, efficient, wise, sincere, loyal, resolute, diligent, personable and virtuous. Besides, all agency is reminded to promote superior quality (individuals and organizations), to behave ethically 
(values and beliefs are acceptable), to obey laws, rules and regulations, and to contribute to the stability and harmony of the country.

To address the issue of integrity among academics in University Kebangsaan Malaysia, a group of researchers developed an instrument to measure integrity. Based on the integrity index produced, the researchers aim to recommend the best solution in tackling integrity issues in the agency. The integrity index will focus on generic practices, teaching and learning practices, research practices and community service practices. Figure 1 is the Academics Model of Integrity that has been developed during the process of developing the instruments.

This model was developed based on values that were statistically proven as reliable and valid to measure integrity. To measure integrity of the generic practice, values of accountability, trust, self-discipline, honesty, responsibility, sincerity, credibility, and prudence must be measured. To measure integrity in teaching and learning, practice based on values of accountability, trust, self-discipline, honesty, responsibility, sincerity, and fairness need to be measured. To measure the integrity of academics in performing research tasks, practices based on accountability, trust, self-discipline, honesty, responsibility, credibility, and efficiency are measured. Similarly, to measure integrity in the services of professionals, practices based on accountability, trust, self-discipline, honest, responsible, sincere, and efficient are measured.

\section{Conclusion}

This concept paper showed that integrity has become a focus in all organizations including government agencies. Effort has been done to promote integrity. However, the issues of integrity continue, and this implies that all agencies need to do more in order to ensure that integrity becomes a culture within the society.

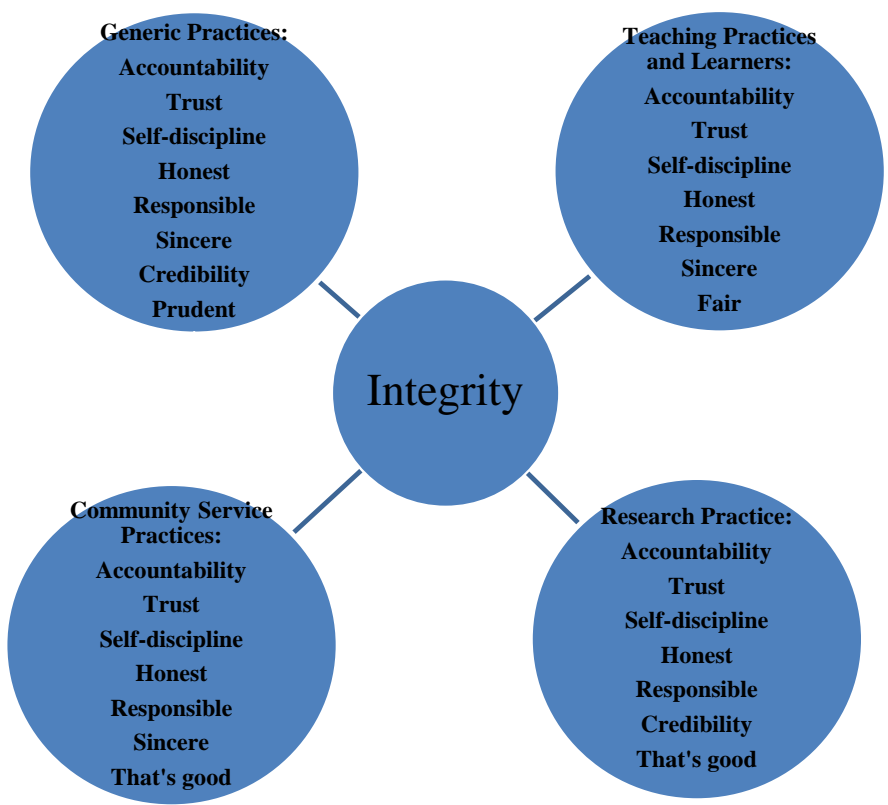

Figure 1. Academics model integrity. 
The strategies might include measuring integrity regularly, conducting integrity campaign or programs at all levels of the organization, and educating citizens about the concept and the values of integrity.

\section{Acknowledgements}

This research is funded by Universiti Kebangsaan Malaysia (UKM) under research scheme No. Grant PP-FPEND-2019 and research Grant KRA-2018-045.

\section{Conflicts of Interest}

The authors declare no conflicts of interest regarding the publication of this paper.

\section{References}

(2004) National Integrity Plan.

(2005). Report of the Commission on Travel Improvement and Management PDRM. PKN.

(2005). Royal Malaysian Police Travel and Management Improvement Commission Report. PKN. Unpublished Report.

Ab. Rahman, I. (2005). Malaysia Outstanding, Glorious and Incredible: Integrity Become an Agenda. Pemikir, 41, 1-13.

Amstrong, E. (2005). Integrity, Transparency and Accountability in Public Administration: Recent Trends, Regional and International Developments and Emerging Issues. United Nation, Economic and Social Affairs.

Dobel, J. P. (1990). Integrity in the Public Service. Public Administration Review, 50, 354-366. https://doi.org/10.2307/976617

Ernst \& Young International (1996). Fraud Survey Report (Global). http://www.ey.com/US/en/SearchResults?query=integrity+and+corruption+1996\&sear choptionscountry name

Mazilan, M., Izal Arif, Z., \& Suzanna, C. M. (2005). Ethics and Integrity in Malaysia: Issues and Challenges. Kuala Lumpur: Institut Integriti Malaysia (IIM).

Megat Ayop, M. A. \& Abd. Halim, A. (2016a). College of Law, the Importance of Cultural Integrity and Work Ethic in Organizations in Malaysia: An Overview. Geografia: Malaysian Journal of Society and Space, 12, 138-149.

Megat Ayop, M. A., \& Abd. Halim, A. (2016b). The Concept of Integrity in the Organization of Royal Malaysian Police: A Preliminary Study. Geografia: Malaysian Journal of Society and Space, 12, 135-147.

Mohd. Tap, S. (2008). Practicing Integrity among Youth. Working Paper in Conjuntion with the National Youth Consultative Council (MPBN) Conference XXVI Year 2008 Meeting on May 24, 2008, at the Hotel Marriot, Putrajaya.

Nik Hairi, O., Azmi, A., \& Azmi, A. M. (2012). Integrity from a Public Complaint Perspective: A Case Study in the Road Transport Department (JPJ) Malaysia. Journal of Social Sciences and Humanities, 7, 141-155.

OECD Report (2009). OECD Annual Report 2009.

http://www.oecd.org/dataoecd/38/39/43125523.pdf

Sulaiman, M. (2005). National Integrity Plan. In M. Mazilan, Z. Izal Arif, \& C. M. Suzan- 
na (Eds.), Ethics and Integrity in Malaysia: Issues and Challenges. Kuala Lumpur: Institut Integriti Malaysia (IIM).

The Oxford Dictionary (2008). The Oxford Dictionary. Oxford: Oxford University Press. 